\title{
Systematic Review on N-3 and N-6 Polyunsaturated Fatty Acid Intake in European Countries in Light of the Current Recommendations - Focus on Specific Population Groups
}

\author{
Isabelle Sioen ${ }^{\mathrm{a}}$ b Lilou van Lieshout $^{\mathrm{c}}$ Ans Eilander $^{\mathrm{e}}$ Mathilde Fleith $^{\mathrm{h}}$ \\ Szimonetta Lohner ${ }^{j, k} \quad$ Alíz Szommer $^{k}$ Catarina Petiscad $^{d}$ Simone Eussen $^{f}$ \\ Stewart Forsyth ${ }^{i}$ Philip C. Calder ${ }^{l, m}$ Cristina Campoy ${ }^{n}$ Ronald P. Mensink ${ }^{g}$ \\ a Department of Public Health, and ' ${ }^{b}$ Department of Food Safety and Food Quality, Ghent University, Ghent, and \\ 'ILSI Europe, and ${ }^{\mathrm{d} B u n g e}$ Europe, Middle-East and Africa, Brussels, Belgium; 'Unilever R\&D Vlaardingen, Vlaardingen, \\ ${ }^{f}$ Danone Nutricia Research, Utrecht, and ${ }^{9}$ Department of Human Biology, NUTRIM School of Nutrition and Translational

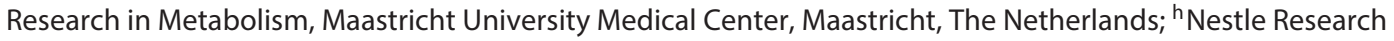 \\ Center, Lausanne, and 'DSM, Kaiseraugst, Switzerland; ' Cochrane Hungary, Clinical Centre, and k Department of \\ Paediatrics, University of Pécs, Pécs, Hungary; 'Faculty of Medicine, University of Southampton, and ${ }^{\mathrm{m}} \mathrm{NIHR}$ Southampton \\ Biomedical Research Centre, University Hospital Southampton NHS Foundation Trust and University of Southampton, \\ Southampton, UK; ${ }^{n}$ Department of Paediatrics, EURISTIKOS Excellence Centre for Paediatric Research, University of Granada, \\ Granada, Spain
}

\section{Keywords}

$\mathrm{N}-3$ polyunsaturated fatty acid $\cdot \mathrm{N}-6$ polyunsaturated fatty acid $\cdot$ Dietary intake $\cdot$ Dietary recommendations

\begin{abstract}
Background: Earlier reviews indicated that in many countries adults, children and adolescents consume on an average less polyunsaturated fatty acids (PUFAs) than recommended by the Food and Agriculture Organisation/World Health Organisation. Summary: The intake of total and individual $n-3$ and n-6 PUFAs in European infants, children, adolescents, elderly and pregnant/lactating women was evaluated systematically. Results: The evaluations were done against recommendations of the European Food Safety Authority. Key Messages: Fifty-three studies from 17 different European countries reported an intake of total n-3 and
\end{abstract}

\section{KARGER}

E-Mail karger@karger.com www.karger.com/anm
C 2017 The Author(s)

Published by S. Karger AG, Basel

This article is licensed under the Creative Commons AttributionNonCommercial-NoDerivatives 4.0 International License (CC BYNC-ND) (http://www.karger.com/Services/OpenAccessLicense). Usage and distribution for commercial purposes as well as any distribution of modified material requires written permission. $\mathrm{n}-6$ PUFAs and/or individual $\mathrm{n}-3$ or $\mathrm{n}-6$ PUFAs in at least one of the specific population groups: 10 in pregnant women, 4 in lactating women, 3 in infants $6-12$ months, 6 in children 1-3 years, 11 in children $4-9$ years, 8 in adolescents $10-18$ years and 11 in elderly $>65$ years. Mean linoleic acid intake was within the recommendation (4 energy percentage [E\%]) in $52 \%$ of the countries, with inadequate intakes more likely in lactating women, adolescents and elderly. Meana-linolenic acid intake was within the recommendation (0.5 E\%) in $77 \%$ of the countries. In $26 \%$ of the countries, mean eicosapentaenoic acid and/or docosahexaenoic acid intake was as recommended. These results indicate that intake of $n-3$ and $n-6$ PUFAs may be suboptimal in specific population groups in Europe.

(c) 2017 The Author(s)

Published by S. Karger AG, Basel

I.S. and L.L. equally shared first authorship.
Ms. Lilou van Lieshout

ILSI Europe

83 Avenue E Mounier, Box 6 BE-1200 Brussels (Belgium)

E-Mail publications@ilsieurope.be 


\section{Introduction}

N-3 and n-6 polyunsaturated fatty acids (PUFAs) particularly the longer chain, more unsaturated members of these families, and also the plant-derived essential members - play a vital role in human health from conception onwards: through every stage of human development, maturation and aging, including roles in cell membrane composition, metabolism, signal transduction and amplification, and in gene expression [1]. An adequate intake (AI) of PUFAs is of critical importance during early life and plays an essential role in supporting growth and development. In addition, for the general population an AI of n-3 and n-6 PUFAs is recommended for the prevention of cardiovascular diseases [2]. However, specific population groups may have relatively higher requirements of these fatty acids and thus are more at risk of inadequate intake. These specific population groups include pregnant and lactating women because of increased PUFA requirements for growth, neurological and immune function of their infants $[3,4]$. Similarly, infants, children and adolescents have relatively high nutrient requirements compared to adults to support rapid growth and development, but complementary foods, school meals and dietary habits during childhood and adolescence may not provide sufficient amounts of nutrients, notably PUFAs [5-8]. Finally, elderly have altered nutrient requirements because of changes in body composition and physical activity and the presence of disease, and altered nutrient intake because of low variety of food consumed, reduced appetite, loss of sensory appreciation of food, dentition and swallowing problems, the presence of disease and social issues, and thus may be at risk of inadequate PUFA intake, besides other important micronutrients [9].

Recent reviews on dietary fat and fatty acid intake in different countries around the world [10-14] are mainly based on data from national dietary surveys that do not include a representative subsample of these specific subgroups of the population. Moreover, in many of these dietary surveys, intake data of individual PUFAs are not reported. Therefore, the aim of this systematic review is to evaluate the available data on $n-3$ and n- 6 PUFA intake in 7 specific population groups in Europe: (1) pregnant women, (2) lactating women, (3) infants (6-12 months), (4) young children (1-3 years), (5) older children (4-10 years), (6) adolescents (10-18 years) and (7) elderly ( $>65$ years). First, an overview of the current available recommendations for PUFA intake in European countries is given. Second, the available intake data are summarised and reported for each group, followed by a discussion of the gaps between reported intake and the European Food Safety Authority (EFSA) recommendations. Third, an overview of studies describing the main food sources of the various PUFAs in these population groups is presented.

\section{Methods}

A more detailed description of the methods employed is given in online supplementary text 1 (for all online suppl. material, see www.karger.com/doi/10.1159/000456723).

Evaluation of Current Recommendations for PUFA Intake in European Countries

For the evaluation of current recommendations for PUFA intake in European countries, we updated the systematic review on dietary reference intake, nutritional goals and dietary guidelines for fats and fatty acids by Aranceta and Pérez-Rodrigo [15] that was published in 2012 with PUFA recommendations for specific population groups in Europe, using the search strategy by Aranceta and Pérez-Rodrigo [15], excluding trans fatty acids. The search was conducted using PubMed and Scopus from January 2011 (date of Aranceta search) to April 20, 2015. In addition, a manual search on individual European country recommendations was performed via Google with latest update done in October 2016.

Evaluation of Current Intake of Total and Specific N-3

and N-6 PUFAs in the European Diet for Specific

Population Groups

Criteria for Considering Studies in This Review

Type of study. Observational studies and national dietary surveys were the primary focus of this review. Randomised control trials or other experimental studies were included only if they reported baseline data and/or data for the control group.

Type of exposure. Studies were included if they reported data on intake of at least one of the following: $\alpha$-linolenic acid (ALA), eicosapentaenoic acid (EPA), docosapentaenoic acid (DPA), docosahexaenoic acid (DHA), total n-3 PUFAs, linoleic acid (LA), arachidonic acid (ARA) or total n-6 PUFAs. We excluded studies reporting only the total PUFA intake without any distinction on individual classes as mentioned above.

Type of population. The following 7 subgroups of the population were the focus of interest in this review: pregnant women, lactating women, infants (6-12 months), young children (1-3 years), older children (4-10 years), adolescents (10-18 years), elderly ( $>65$ years). The age ranges are defined in accordance with the EFSA Comprehensive European Consumption Database [16]. Studies in specific disease populations were excluded. Only studies conducted in European countries were included. Inclusion and exclusion criteria can be found in the abstract review form at PROSPERO with registration number CRD42014014717.

Period of time for exposure measurement. Studies conducted after January 1, 2000 were eligible for inclusion. Studies conducted before 2000 , but reported in a publication published after 2000 , were excluded.
40

Ann Nutr Metab 2017;70:39-50 DOI: $10.1159 / 000456723$
Sioen et al. 
Search Methods for Identification of Studies

PubMed, Scopus and Cochrane Central Register of Controlled Trials (CENTRAL) databases were searched for papers published from January 2000 until November 2015, using text words with appropriate truncation and relevant indexing terms. The search was in the form (n-3 and n-6 PUFA terms) and (terms for intake) and (terms for the specific subgroup considered) and (limit to humans) and (limit to 2000 - current). The full search strategy for the Ovid MEDLINE database can be accessed via PROSPERO file CRD42014014717; the searches of other databases were based on this strategy. Reference lists of all eligible papers and relevant systematic reviews were searched for additional studies.

\section{Data Selection}

The titles and abstracts of studies identified by the search were screened by a single reviewer, and clearly irrelevant studies were excluded. The full text reports of all potentially relevant studies were obtained and assessed independently for eligibility by 2 independent reviewers. The systematic review software Covidence (www.covidence.org) was used to facilitate screening of literature. Any disagreement was resolved by discussion.

\section{Data Extraction}

Standardised forms were used for data extraction and management. For each included study, the following data were extracted and brought together into one large database: name of first author, year of publication, year(s) of data collection, participant characteristics (age, sex, $n$, the subgroup they belong to), method used for dietary assessment and intake data on total energy ( $\mathrm{MJ} /$ day), total fat (g/day and energy percentage [E\%]), total PUFAs (g/day and E\%), total n-6 PUFAs (g/day and E\%), LA (g/day and E\%), ARA (mg/day), total n-3 PUFAs (g/day and E\%), ALA (g/day and E\%), EPA (mg/day), DPA (mg/day), and DHA (mg/day). When necessary, units of measurement were converted to a standard form (g/day, $\mathrm{mg} /$ day, or $\mathrm{E} \%$ ) expressed in mean and SD to facilitate comparison across studies. When only median and quartiles were given, the mean was calculated as the average of the median, 25th (P25) and 75th (P75) percentiles. The standard deviation was calculated as P75-P25/1.35. Unpublished data for countries that participated in the HELENA study in adolescents were included based on personal communication with the researchers involved, as the original publication only reported data of the overall international sample [17].

\section{Data Assessment}

All fatty acid intake data were evaluated against the EFSA recommendations [18], which are the most recent recommendations that are set by a recognised Europe-wide health authority. Because of the absence of total n-3 and total n-6 PUFA intake recommendations, ALA and LA recommendations were used to evaluate total n-3 or n-6 PUFA intake. ALA and LA are the biggest contributors to total n-3 and n-6 PUFA intake, respectively. Per country and population group, intake data were extracted to evaluate whether the intake of different PUFAs was in line with the EFSA recommendations. Where multiple datasets were available for one country and specific population group, the average of these datasets was calculated (weighted for $n$ ). This average was used to define whether the intake data were in line or below the relevant EFSA recommendation.

Dietary PUFA Intake in Europe
Evaluation of Major Dietary Contributors to PUFA Intake

Another literature search was undertaken in PubMed to find data on dietary sources of PUFAs in the considered population subgroups and data on the PUFA composition of human milk. The search was conducted with terms describing fatty acids, diet and habits. The full search strategy can be found on PROSPERO with registration number CRD42014014717. In addition, all identified publications with intake data were screened for relevant data on food sources. For data on dietary sources excluding human milk, studies were excluded, if the data were collected before 2000. For data on human milk, publications from 1990 onwards were included because of limited available data published after 2000.

\section{Results}

\section{Evaluation of Recommendations for PUFA Intake in European Countries}

In addition to the EFSA and Food and Agriculture Organisation (FAO)/World Health Organisation (WHO) recommendations, we identified 6 individual country and 4 multi-country recommendations for PUFA intake. In general, recommendations were developed by scientific experts and health authorities after commissioning expert systematic evidence-based reviews of mainly human observational and intervention studies to guide the authority's decision. Table 1 gives an overview of the recommendations identified.

The criteria used to set specific recommendations (Table 1) are not always clearly described, but include provision for adequate growth for infants and children, prevention of clinical deficiency and provision for good health, encompassing prevention of cardiovascular diseases after the age of 2 years.

Mostly, 2 kinds of dietary reference values (DRVs) were derived for PUFAs, the AI, for example, set by EFSA and many European countries, and the acceptable macronutrient distribution range, set by $\mathrm{FAO} / \mathrm{WHO}$ [19]. For LA, the FAO/WHO additionally set an estimated average requirement.

In general, the DRVs for different n-3 and n-6 PUFAs for Europe and European countries differ with regard to age group, type of fatty acid and unit of expression, which made it difficult to compare. In general, DRVs were reported for LA, ALA and EPA + DHA or DHA, while no recommendations were reported for DPA, and for ARA recommendations were only reported for infants 0-6 months of age. If guidelines were formulated for pregnant and breastfeeding women, they were focused on a specific increase in the intake of DHA. Recommendations for children $>2$ years of age were not age-specific and were often similar to those for adults. For elderly, no rec-

Ann Nutr Metab 2017;70:39-50 


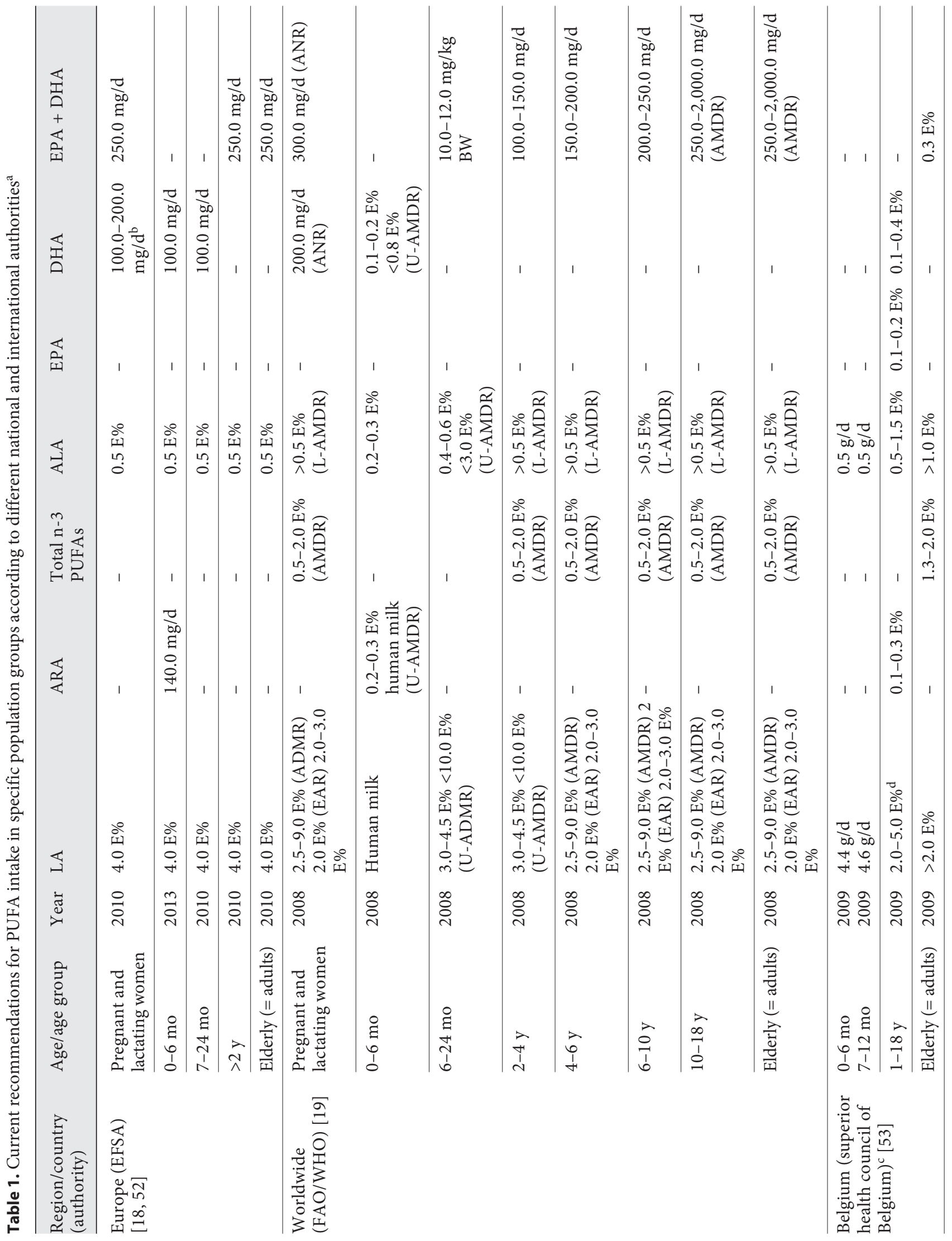




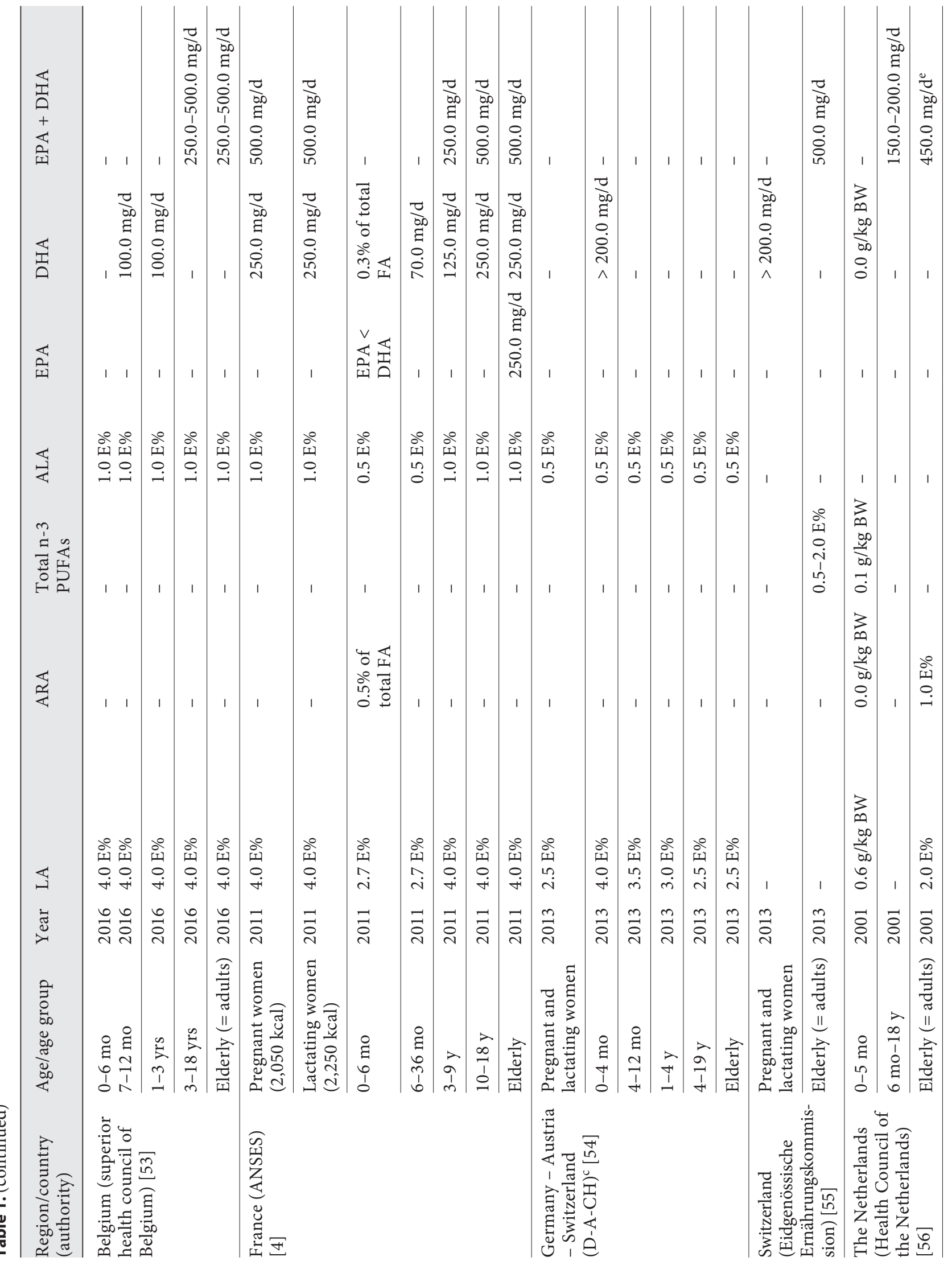




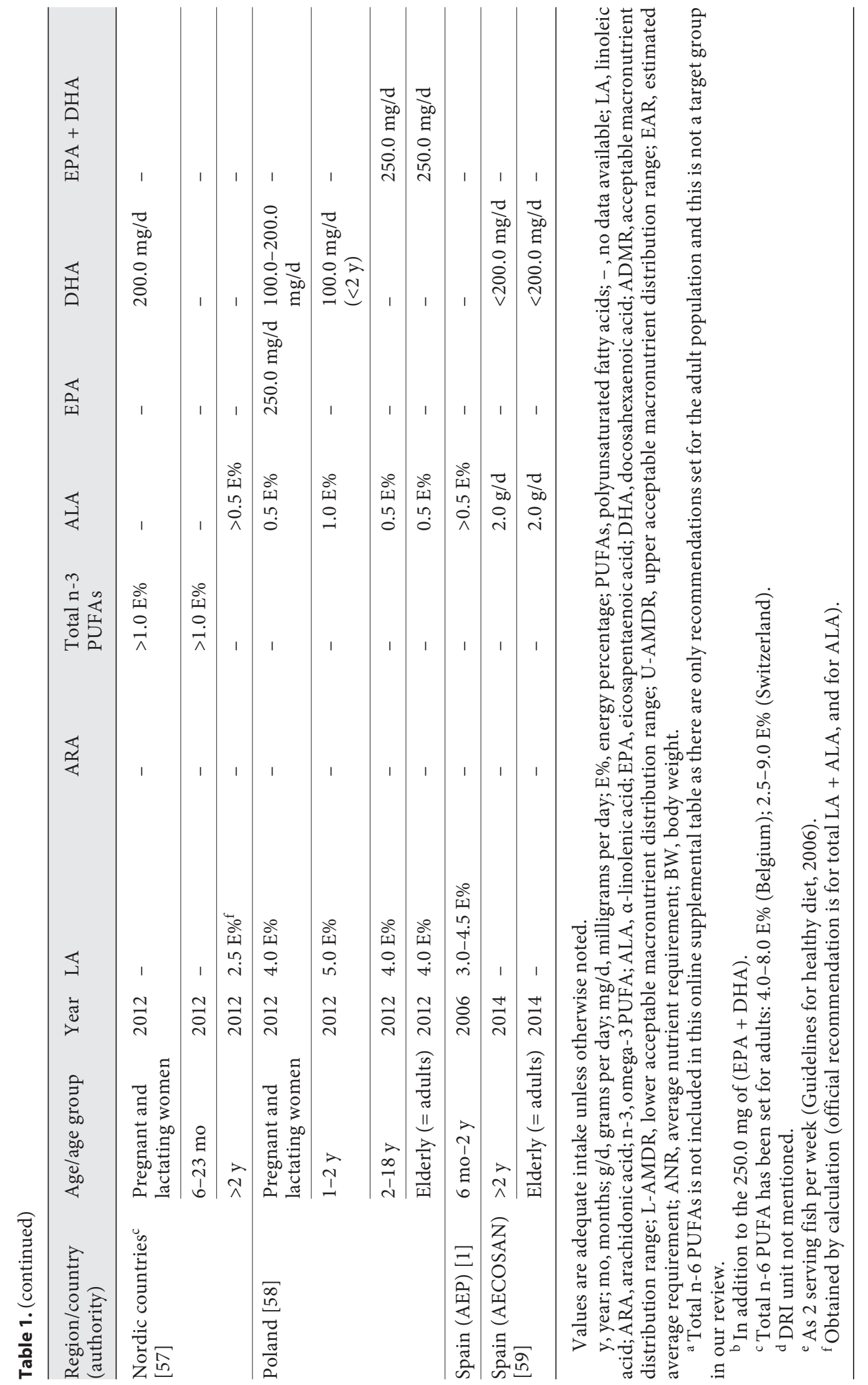


Table 2. Overview of European countries meeting n-3 and n-6 PUFA intake recommendations per population group if compared with the EFSA recommendations (percentage of countries with adequate intake)

\begin{tabular}{|c|c|c|c|c|c|c|c|c|c|}
\hline & \multirow{2}{*}{$\begin{array}{l}\text { Studies, } \\
n\end{array}$} & \multirow{2}{*}{$\begin{array}{l}\mathrm{N} \\
\text { countries }\end{array}$} & \multirow{2}{*}{$\begin{array}{l}\mathrm{N} \text { subjects } \\
\text { included }\end{array}$} & \multicolumn{6}{|c|}{ Evaluation against recommendations (percentage of countries with adequate intake) } \\
\hline & & & & total n-6 PUFAs & LA & $\mathrm{ARA}^{\mathrm{a}}$ & total n-3 PUFAs & ALA & $\mathrm{EPA}+\mathrm{DHA}$ \\
\hline Recommendations & & & & $4.0 \mathrm{E} \%{ }^{\mathrm{b}}$ & $4.0 \mathrm{E} \%$ & - & $0.5 \mathrm{E} \%{ }^{\mathrm{b}}$ & $0.5 \mathrm{E} \%$ & RI: $250+100-200 \mathrm{mg} / \mathrm{d} \mathrm{DHA}$ \\
\hline Pregnant women & 10 & 11 & 6,033 & $66(2$ out of 3$)$ & 75 (3 out of 4$)$ & 3 reported & $100(3$ out of 3$)$ & $100(4$ out of 4$)$ & $33(3$ out of 9$)$ \\
\hline Lactating women & 4 & 4 & 293 & $0(0$ out of 1$)$ & $0(0$ out of 3$)$ & 1 reported & $100(4$ out of 4$)$ & $100(2$ out of 2$)$ & $50(1$ out of 2$)$ \\
\hline Recommendations & & & & $4.0 \mathrm{E} \% \mathrm{~b}$ & $4.0 \mathrm{E} \%$ & - & $0.5 \mathrm{E} \%^{\mathrm{b}}$ & $0.5 \mathrm{E} \%$ & $100.0 \mathrm{mg} / \mathrm{d}^{\mathrm{DH}} \mathrm{A}^{\mathrm{c}}$ \\
\hline Infants $6-12 \mathrm{mo}$ & 3 & 3 & 606 & $100(2$ out of 2$)$ & $100(2$ out of 2$)$ & 1 reported & $100(2$ out of 2$)$ & $100(2$ out of 2$)$ & $0(0$ out of 2$)$ \\
\hline Children 1-3 y & 6 & 6 & 1,797 & 66 (2 out of 3$)$ & 75 ( 3 out of 4$)$ & 1 reported & $100(4$ out of 4$)$ & 75 (3 out of 4$)$ & $0(0 \text { out of } 2)^{c}$ \\
\hline Recommendations & & & & $4.0 \mathrm{E} \% \mathrm{~b}$ & $4.0 \mathrm{E} \%$ & - & $0.5 \mathrm{E} \%^{\mathrm{b}}$ & $0.5 \mathrm{E} \%$ & $\geq 250.0 \mathrm{mg} / \mathrm{d}$ \\
\hline Children 4-9 y & 11 & 10 & 10,102 & 55 (5 out of 9 ) & $66(2$ out of 3$)$ & 2 reported & 78 (7 out of 9$)$ & $100(3$ out of 3$)$ & $0(0$ out of 3$)$ \\
\hline Adolescents & & & & & & & & & \\
\hline $10-18 y$ & 8 & 11 & 4,988 & 50 ( 1 out of 2$)$ & 44 (4 out of 9 ) & 8 reported & $100(3$ out of 3$)$ & $70(7$ out of 10$)$ & $20(2$ out of 10$)$ \\
\hline Elderly $>65$ y & 11 & 9 & 9,091 & 66 (2 out of 3$)$ & 33 (2 out of 6$)$ & 4 reported & $66(2$ out of 3$)$ & $50(3$ out of 6$)$ & $50(3$ out of 6$)$ \\
\hline $\begin{array}{l}\text { Total of all } \\
\text { population groups }\end{array}$ & & & & 61 (14 out of 23$)$ & 52 (16 out of 31$)$ & 20 reported & 89 (25 out of 28$)$ & 77 (24 out of 31$)$ & 26 (9 out of 34$)$ \\
\hline
\end{tabular}

y, year; mo, months; mg/d, milligrams per day; E\%, energy percentage; EFSA, European Food Safety Authority; PUFAs, polyunsaturated fatty acids; LA, linoleic acid; ARA, arachidonic acid; n-6, omega-6 PUFA; n-3, omega-3 PUFA; ALA, $\alpha$-linolenic acid; EPA, eicosapentaenoic acid; DHA, docosahexaenoic acid; RI, reference intake.

${ }^{a}$ No recommendation, only number of studies with intake data.

${ }^{\mathrm{b}}$ Based on EFSA recommendations for LA and ALA.

${ }^{\mathrm{c}}$ For children $>2$ y recommendation $250 \mathrm{mg}$ EPA + DHA per day.

ommendations were derived, as no specific needs for any of the PUFAs were deemed evident.

Based on these outcomes, and as explained in the method section, the EFSA recommendations [18] have been selected to evaluate adequacy of fatty acid intake data in the current review. In the absence of EFSA recommendations for elderly, adult recommendations were used.

\section{Evaluation of Intake of Total and Specific N-3 and N-6 PUFAs}

Altogether 5,404 titles and abstracts were identified via electronic, bibliographic and additional expert searches, and 267 of them appeared to be potentially relevant. Finally, 49 studies fulfilled the inclusion criteria. For pregnant women, 10 different publications were included, reporting PUFA intake data in 11 different European countries. For lactating women, only 4 studies from 4 different countries were included, all with a limited sample size (14-63 women). For infants aged 6-12 months, only 3 studies from 3 different countries were found, of which the study in German infants reported intake data, when children were 6 and 9 months old [20]. For young children aged 1-3 years, 6 studies from 6 different countries were included. For older children aged $4-9$ years, 11 studies from 10 countries were identified, of which some studies reported intake in multiple countries. For adolescents aged 10-19 years, 8 studies from 11 different countries reported data on individual PUFA intake. For elderly

Dietary PUFA Intake in Europe aged $\geq 65$ years, 11 studies from 9 countries were included of which one study from Hungary [21] reported data in elderly aged $\geq 60$ years. Details of intake data can be found in online supplementary Tables 1-7.

In general, intake data were reported for total n-6 PUFAs, LA, total n-3 PUFAs, ALA, EPA and DHA, whereas for DPA and ARA, very little intake data were found.

Table 2 gives an overview of available intake data and summarises the proportions of countries where current intake data were in line with the EFSA recommendations for each population group. Detailed information about the countries included in each population group can be found in the online supplementary Tables 1-7. Across all population groups, mean LA intake was below the recommendation of $\geq 4 \mathrm{E} \%$ in $48 \%$ of the countries, with low intake more likely in lactating women, adolescents and elderly, whereas mean ALA intake was below the recommendation of $\geq 0.5 \mathrm{E} \%$ in $23 \%$ of the countries (Table 2). Across all population groups, mean EPA and/or DHA intake was lower than the EFSA recommendation in $74 \%$ of the countries, and low intake was of concern in pregnant and lactating women and in infants, children and adolescents.

\section{Evaluation of Major Dietary Contributors to PUFA Intake}

Dietary Sources of Individual PUFAs

Data on the contribution of different food groups and supplements to the intake of various PUFAs were limited

Ann Nutr Metab 2017;70:39-50

DOI: $10.1159 / 000456723$ 
to 3 studies, including a Belgian study in children aged 2.5-6.5 years [22], the HELENA study in adolescents aged 12.5-17.5 years [17] and a study in Dutch elderly aged $\geq 70$ years [23]. In Belgian children, fats and oils were the major contributors to intakes of LA (23.6\%) and ALA (33.1\%), followed by cereal products with 17.6 and $13.5 \%$, respectively [22]. Meat, poultry and eggs were the main contributors to ARA intake (72.0\%), and fish and seafood were the main contributors to EPA (83.5\%), DPA (57.8\%) and DHA (75.7\%) intake [22]. In adolescents in the multiple country HELENA study [17], the food group "meat, fish, eggs and meat alternatives" was the largest contributor to the intake of LA (31.7\%), ALA (21.5), ARA (54.2\%), EPA (92.3\%), DPA (94.9\%) and DHA (85.8\%). In Dutch elderly, fats and oils were the main contributor to LA (39\%) and ALA (36\%) intake, whereas fish and shellfish (29\%) and meat and meat products (28\%) were the main contributors to EPA and DHA intake.

Individual PUFA Content of Human Milk

LA and ALA are the major PUFAs present in human milk. According to a review of 14 studies from 9 European countries [24, 25], the median (range) content of human milk is $11.0 \% \mathrm{wt} / \mathrm{wt}(6.9-16.4)$ for LA and $0.9 \% \mathrm{wt} / \mathrm{wt}(0.7-1.3)$ for ALA. A descriptive meta-analysis including 65 studies of 2,474 women worldwide indicated a mean \pm SD concentration of DHA and ARA in human milk of $0.32 \pm 0.22$ and $0.47 \pm 0.13 \%$ of total fatty acids, respectively [26]. European countries tended to report higher DHA levels [27], with the highest DHA concentrations in coastal regions such as Greece, Italy and Spain. Detailed information about PUFA content of human milk can be found in the online supplementary Table 8 [26]. DHA levels in human milk vary considerably among women and are strongly influenced by maternal diet, for example, fish and seafood intake [27-30], whereas ARA concentrations in human milk are less sensitive to maternal dietary ARA intake $[26,30]$.

\section{Discussion}

We provided an overview of the available data on recommendations, dietary intake and sources of total and individual n-3 and n-6 PUFAs in European pregnant women, lactating women, infants, young children, older children, adolescents and elderly.

\section{Recommendations}

Since the review of Aranceta and Pérez-Rodrigo [15] published in 2012, we found that some recommendations hadnotbeenupdated(FAO/WHO,EFSA, TheNetherlands, Spain), while others had (France, Nordic countries, Belgium). In addition, we identified new recommendations that were not published at the time of the earlier review (DACH countries - Germany, Austria, Switzerland, Poland; France and Spain for infants and children). Similar to FAO/WHO and EFSA, no specific dietary recommendations were formulated for elderly in Europe, despite the fact that some countries (e.g., France 2001) discussed the specific dietary needs of the elderly [31].

For ARA, recommendations are limited to infants aged 0-6 months and were based on human milk content. However, the functional effect of increased ARA intake in this age group, and in other age groups, is still much discussed $[32,33]$. The role of preformed DHA in visual development and brain growth and functioning in foetal life and early infancy has been demonstrated and translated into specific recommendations for pregnant and lactating women and infants. After the age of 2 years, based largely on their preventive effect on CVD and beneficial effects for neurodevelopment, recommendations have been formulated for EPA + DHA, since these PUFAs are often consumed in combination, for instance in seafood and supplements. In contrast to recommendations in European countries and EFSA, some authorities, such as those of Australia and NewZealand [34] have set an AI based on the concept of essentiality, that is, on the median intake for children and adults in a population without apparent essential fatty acid deficiency, resulting in generally lower recommended intakes. While no recommendations for DPA were formulated in Europe, the health authority from Australia and New Zealand included DPA in its recommendations, that is, the recommended intake for long chain n-3 PUFAs including EPA + DPA + DHA.

Germany and The Netherlands recently reviewed their intake recommendations, but did not set any reference value for fatty acids, and rather formulated food-based dietary guidelines [35, 36]. Moreover, 2 important authorities, the US Institute of Medicine and the WHO Nutrition Guidance Expert Advisory Group intend to update their PUFA intake recommendations [37]. In 2014, the US and Canadian governments collaboratively indicated that nutrient reference values for n-3 PUFAs needed to be updated with priority, based on public health and/or policy importance. The committee is considering the incorporation of chronic disease endpoints into the setting of dietary reference intake values [38].
46

Ann Nutr Metab 2017;70:39-50 DOI: $10.1159 / 000456723$
Sioen et al. 


\section{Intake Data}

In summary, we found that the current information on PUFA intake, with especially individual long chain PUFAs in specific age groups being at risk for an inadequate PUFA intake across Europe is limited, and identified many gaps in the current knowledge. Our findings show that EFSA recommendations for intake of LA, ALA and EPA + DHA were not met in almost half, a quarter and 3-quarters of the countries, respectively. This is in line with findings of earlier studies that have evaluated intakes of these fatty acids in children, adolescents and adults worldwide [12, 13].

The lowest number of available studies was found for lactating women and infants. However, these population groups are of particular interest as PUFA intake is very important for rapid brain growth and development during infancy. In addition, our findings indicate that there is a lack of data on ARA and DPA intakes. The scarcity of data on ARA and DPA intakes limits the assessment of intake adequacy, especially for at-risk population groups. A potential explanation is that information on individual PUFAs in the European food composition tables is often missing. Therefore, it may be necessary to combine information from different food composition tables to make a complete estimation of the individual PUFA intake. In future, it would be relevant that ARA and DPA are also included in food composition analyses.

Furthermore, large heterogeneity between studies with regard to methodologies and data presentation, made it difficult to compare the available intake data across countries. First, studies used different methods for dietary assessments (e.g., $24 \mathrm{~h}$ recall, food frequency questionnaires, dietary record). Some of these methods assess intake over a short term (1-3 days), which may not capture the intake of foods that are not consumed on a daily basis (e.g., fish and seafood) and consequently underestimate the intake of EPA and DHA. However, when dietary assessments of the study population cover all weekdays and seasons, the estimation of mean intakes on the population level will be reasonable [39]. In a limited number of identified studies, statistical methods were applied to correct this between-day variability. However, even when diets were evaluated over a longer period, foods may have been grouped together (e.g., n-3 PUFArich fish and fish less rich in n-3 PUFAs), which may reduce the specificity of intake data. Second, some studies took the use of food supplements into consideration [4042] or even selected participants based on very high seafood consumption (a survey in French coastal populations) [43], while others specifically excluded fish oil supplement users [44-46] and some studies just did not

Dietary PUFA Intake in Europe report whether or not supplements were taken into consideration. Also, in some countries the use of food supplements in general (not specifically, n-3 PUFA supplements) by pregnant and lactating women is quite common (e.g., in the study of Rodriguez-Bernal, $55.8 \%$ of the women report the use of multivitamin supplements) [42], which may explain the large variation in PUFA intake. Unfortunately, no data could be found on the average use of n-3 PUFA supplements by European pregnant women, which indicated the need to collect data on supplement use in addition to dietary intake in future studies. Third, different metrics were used to represent the intake data: some studies reported the median, while others used the arithmetic or geometric mean, sometimes in combination with the standard deviation or with a percentile range. This shows a need to harmonise the way data on PUFA intake is presented; for example, in case of skewed distributions (e.g., EPA and DHA intakes) medians should be reported. The studies included in our review mainly reported data in means and only a few reported medians. Moreover, comparing the mean PUFA intake of a population with PUFA recommendation does not allow to determine the percentage of the population not meeting the PUFA recommendation. To do so, the distribution of the intake in the population has to be known. Fourth, different units to express the intake data were used: intake of fatty acids can be expressed in $(\mathrm{m}) \mathrm{g} /$ day, $\mathrm{E} \%$ or \% of total fat. As it was not always possible to convert intake to a common unit based on the available information in the publication, comparisons between different studies and evaluation of EFSA recommendations were not possible for some data.

This review also showed that information on food and food groups contributing to the intake of different PUFAs, and in which amount they contribute, is largely lacking and if available, food groups did often report data for individual PUFAs and were not comparable between studies.

\section{Strengths and Limitations}

This study has some important strengths. First, the overview provided is based on the application of a systematic and standardised approach to screen the literature and identify the studies to be included. Second, data extraction from the selected studies was conducted in a harmonised way to obtain useful data for comparison. However, some limitations also need to be mentioned. First, most of the available studies were not based on a random sampling procedure or on a national representative sample. Second, the EFSA recommendations for LA and ALA intakes were used to evaluate if intake of total n-6 PUFAs

Ann Nutr Metab 2017;70:39-50 DOI: $10.1159 / 000456723$ 
and total n-3 PUFAs was adequate, which may have led to an overestimation of countries with sufficient total n-6 and n-3 PUFA intakes. While the approximation is small for n-6 PUFAs (LA contributes on an average to 99\% of total n-6 PUFA intake), it is higher for n-3 PUFAs (ALA contributes on an average to $\sim 80 \%$ of n-3 PUFA intake).

\section{Recommendations for Future Research}

Given the limited data available on individual n-3 and n-6 PUFA intakes in specific population groups in Europe, our key recommendation is that the EU should develop harmonised data collection systems that will provide a robust and reliable database on the intake of individual PUFAs. This would be needed to establish evidence-based guidelines for public health programs aiming to improve fatty acid intake and for monitoring and evaluating the effectiveness of these programs. Moreover, greater national commitment to and consistency in the provision of intake data is required to allow reasonable comparative analyses between different countries. Future more detailed intake data should be used to reevaluate the current recommendations for the general population and specific population groups, including those with different pathologies and genetic polymorphisms. This would particularly be relevant for ARA and DPA for which extremely limited data are available. While studies in infants have suggested the role of ARA in combination with DHA on physical growth and cognitive development [47-50], more recent data indicate that ARA and its derivatives may also play key roles in cardiovascular, inflammatory and immune functions, which have not yet been adequately investigated [34]. Similarly, the potential role of DPA in cardiovascular disease, immune function and psychiatric and cognitive health needs further investigation [51].

\section{Conclusion}

The available data indicate that mean intake of EPA and DHA and to a lesser extent of LA and ALA may be suboptimal compared to EFSA recommendations for a significant part of specific population groups in Europe. More nationally representative surveys, including subsamples of specific population groups and data on relevant individual PUFAs are required to clarify the need for specific public health measures to optimise PUFA intake in Europe. Also, recommendations for nutrient requirements should be developed for the elderly population and recommendations for intake of total n-6 and n-3 PUFAs in all population groups.

\section{Disclosure Statement}

Dr. Catarina Petisca is an employee of Bunge Europe, Dr. Mathilde Fleith is an employee of Nestlé Research Centre, Dr. Ans Eilander is an employee of Unilever Research and Development, Dr. Simone Eussen is an employee of Danone Nutricia Research, Prof. Stewart Forsyth is a consultant for DSM Nutritional Products Ltd. and Prof. Philip C. Calder is an advisor to Pronova BioPharma (part of BASF), Danone Research Centre for Specialized Nutrition, DSM, Cargill, and Smartfish.

\section{Acknowledgements}

This work was conducted by an expert group of the European branch of the International Life Sciences Institute (ILSI Europe). The authors would like to thank Prof. Gerhard Hornstra for his contributions during the initial stages of the manuscript. This publication was coordinated by Ms. Lilou van Lieshout, Scientific Project Manager at ILSI Europe. The expert group received funding from the ILSI Europe Nutrient Intake Optimisation Task Force and Early Nutrition and Long-Term Health (formerly Metabolic Imprinting) Task Force. Industry members of these task forces are listed on the ILSI Europe website (www.ilsi.eu). In 2016, current member companies of the task forces are BASF SE, Danone, DSM, FrieslandCampina, Nestlé, SQM Europe, Ülker Bisküvi and Unilever (Nutrient Intake Optimisation Task Force) and Abbott Nutrition, Arla Foods, Danone, DSM, Mead Johnson Pediatric Nutrition Institute and Nestlé (Early Nutrition and Long-Term Health Task Force). For further information about ILSI Europe, please email info@ilsieurope.be or call +32 277100 14. The opinions expressed herein and the conclusions of this publication are those of the authors and do not necessarily represent the views of ILSI Europe nor those of its member companies.

We acknowledge Luis A. Moreno who gave permission to publish the HELENA PUFA intake data per survey centre.

References

1 Gil A, Serra-Majem L, Calder PC, Uauy R: Systematic reviews of the role of omega- 3 fatty acids in the prevention and treatment of disease. Br J Nutr 2012;107:S1-S2.

2 Hooper L, Martin N, Abdelhamid A, Davey Smith G: Reduction in saturated fat intake for cardiovascular disease. Cochrane Database Syst Rev 2015;6:D011737.

-3 European Food Safety Authority NDA Panel: Scientific opinion on nutrient requirements and dietary intakes of infants and young children in the European Union. EFSA J 2013;11: 3408 .

4 Agence Nationale de Sécurité Sanitaire de L'alimentation (ANSES): Actualisation des Apports Nutritionnels Conseillés Pour Les Acides Gras No. Saisine No 2006-SA-0359. Maisons-Alfort, ANSES, 2011.

$\checkmark 5$ Li D: Omega-3 polyunsaturated fatty acids and non-communicable diseases: meta-analysis based systematic review. Asia Pac J Clin Nutr 2015;24:10-15.
48

Ann Nutr Metab 2017;70:39-50

DOI: $10.1159 / 000456723$
Sioen et al. 
-6 Szostak-Wegierek D, Klosiewicz-Latoszek L, Szostak WB, Cybulska B: The role of dietary fats for preventing cardiovascular disease. A review. Rocz Panstw Zakl Hig 2013;64:263269.

7 Flachs P, Rossmeisl M, Kopecky J: The effect of n-3 fatty acids on glucose homeostasis and insulin sensitivity. Physiol Res 2014;63(suppl 1):S93-S118.

${ }_{8}$ Wu JH, Lemaitre RN, King IB, Song X, Psaty BM, Siscovick DS, Mozaffarian D: Circulating omega- 6 polyunsaturated fatty acids and total and cause-specific mortality: the cardiovascular health study. Circulation 2014;130:12451253.

9 World Health Organization: Nutrition for Older Persons. 2015. http://www.who.int/ nutrition/topics/ageing/en/index1.html (accessed August 2015).

10 Eilander A, Harika RK, Zock PL: Intake and sources of dietary fatty acids in Europe: are current population intakes of fats aligned with dietary recommendations? Eur J Lipid Sci Technol 2015;117:1370-1377.

11 Mozaffarian D, Micha R, Wallace S: Effects on coronary heart disease of increasing polyunsaturated fat in place of saturated fat: a systematic review and meta-analysis of randomized controlled trials. PLoS Med 2010; 7:e1000252.

12 Harika RK, Cosgrove MC, Osendarp SJ, Verhoef P, Zock PL: Fatty acid intakes of children and adolescents are not in line with the dietary intake recommendations for future cardiovascular health: a systematic review of dietary intake data from thirty countries. $\mathrm{Br} \mathrm{J}$ Nutr 2010;106:307-316.

13 Harika RK, Eilander A, Alssema M, Osendarp SJ, Zock PL: Intake of fatty acids in general populations worldwide does not meet dietary recommendations to prevent coronary heart disease: a systematic review of data from 40 countries. Ann Nutr Metab 2013;63:229-238.

14 Micha R, Khatibzadeh S, Shi P, Fahimi S, Lim S, Andrews KG, Engell RE, Powles J, Ezzati M, Mozaffarian D; Global Burden of Diseases Nutrition and Chronic Diseases Expert Group NutriCoDE: Global, regional, and national consumption levels of dietary fats and oils in 1990 and 2010: a systematic analysis including 266 country-specific nutrition surveys. BMJ 2014;348:g2272.

15 Aranceta J, Pérez-Rodrigo C: Recommended dietary reference intakes, nutritional goals and dietary guidelines for fat and fatty acids: a systematic review. Br J Nutr 2012;107(suppl 2):S8-S22.

16 European Food Safety Authority (EFSA): Use of the EFSA Comprehensive European Food Consumption Database in Exposure Assessment. EFSA J 2011;9:2097.

17 Vyncke KE, Libuda L, De Vriendt T, Moreno LA, Van Winckel M, Manios Y, Gottrand F, Molnar D, Vanaelst B, Sjöström M, GonzálezGross M, Censi L, Widhalm K, Michels N, Gilbert CC, Xatzis C, Cuenca García M, de Heredia FP, De Henauw S, Huybrechts I;
HELENA consortium: Dietary fatty acid intake, its food sources and determinants in European adolescents: the HELENA (Healthy Lifestyle in Europe by Nutrition in Adolescence) study. Br J Nutr 2012;108: 2261-2273.

18 European Food Safety Authority NDA Panel: Scientific opinion on dietary reference values for fats, including saturated fatty acids, polyunsaturated fatty acids, monounsaturated fatty acids, trans fatty acids, and cholesterol. EFSA J 2010;8:1461.

19 FAO/WHO Expert Consultation on Fats and Fatty Acids in Human Nutrition: Fats and Fatty Acids in Human Nutrition: Report of an Expert Consultation; 10-14 November 2008. Geneva, Food and Agriculture Organization of the United Nations, 2010.

20 Schwartz J, Dube K, Alexy U, Kalhoff H, Kersting M: PUFA and LC-PUFA intake during the first year of life: can dietary practice achieve a guideline diet? Eur J Clin Nutr 2010; 64:124-130.

21 Szeitz-Szabó M, Bíró L, Bíróa Gy, Sali J: Dietary survey in Hungary, 2009. Part I. macronutrients, alcohol, caffeine, fibre. Acta Aliment Hung 2011;40:142-152.

22 Sioen I, Huybrechts I, Verbeke W, Camp JV, De Henauw S: N-6 and n-3 PUFA intakes of pre-school children in Flanders, Belgium. Br J Nutr 2007;98:819-825.

23 Ocke MC, Buurma-Rethans EJM, de Boer EJ, Wilson-van den Hooven C, Etemad-Ghameslou Z, Drijvers JJMM, van Rossum CTM: Diet of Community-Dwelling Older Adults: Dutch National Food Consumption Survey Older Adults 2010-2012. RIVM Rapport050413001. Bilthoven, RIVM, 2013.

24 Koletzko B, Thiel I, Abiodun PO: The fatty acid composition of human milk in Europe and Africa. J Pediatr 1992;120(4 pt 2):S62-S70.

25 World Health Organization: Fats and Oils in Human Nutrition: Report of a Joint Expert Consultation, ed 57. Geneva, WHO/FAO, 1993.

26 Brenna JT, Varamini B, Jensen RG, DiersenSchade DA, Boettcher JA, Arterburn LM: Docosahexaenoic and arachidonic acid concentrations in human breast milk worldwide. Am J Clin Nutr 2007;85:1457-1464.

27 Lauritzen L, Hansen HS, Jørgensen MH, Michaelsen KF: The essentiality of long chain n-3 fatty acids in relation to development and function of the brain and retina. Prog Lipid Res 2001;40:1-94.

28 Huang HL, Chuang LT, Li HH, Lin CP, Glew RH: Docosahexaenoic acid in maternal and neonatal plasma phospholipids and milk lipids of Taiwanese women in Kinmen: fatty acid composition of maternal blood, neonatal blood and breast milk. Lipids Health Dis 2013;12:27.

29 Gao YX, Zhang J, Wang C, Li L, Man Q, Song P, Meng L, Lie O, Frøyland L: The fatty acid composition of colostrum in three geographic regions of China. Asia Pac J Clin Nutr 2013; 22:276-282.
30 Antonakou A, Skenderi KP, Chiou A, Anastasiou CA, Bakoula C, Matalas AL: Breast milk fat concentration and fatty acid pattern during the first six months in exclusively breastfeeding Greek women. Eur J Nutr 2013; 52:963-973.

31 Martin A: Apports Nutritionnels Conseillés Pour la Population Française. Paris, Tec \& Doc Lavoisier, 2000.

-32 Crawford MA, Wang Y, Forsyth S, Brenna JT: The European food safety authority recommendation for polyunsaturated fatty acid composition of infant formula overrules breast milk, puts infants at risk, and should be revised. Prostaglandins Leukot Essent Fatty Acids 2015;102-103:1-3.

33 Lauritzen L, Fewtrell M, Agostoni C: Dietary arachidonic acid in perinatal nutrition: a commentary. Pediatr Res 2015;77:263-269.

34 Capra S: Nutrient Reference Values for Australia and New Zealand: Including Recommended Dietary Intakes, ed 1. Canberra, New Zealand Ministry of Health, 2006.

35 Kromhout D, Spaaij CJK, de Goede J, Weggemans RM: The 2015 Dutch food-based dietary guidelines. Eur J Clin Nutr 2016;70:869878.

36 Wolfram G, Bechthold A, Boeing H, Ellinger $\mathrm{S}$, Hauner $\mathrm{H}$, Kroke A, Leschik-Bonnet E, Linseisen J, Lorkowski S, Schulze M, Stehle P, Dinter J; German Nutrition Society: Evidence-based guideline of the German nutrition society: fat intake and prevention of selected nutrition-related diseases. Ann Nutr Metab 2015;67:141-204.

37 World Health Organization: WHO Handbook for Guideline Development, ed 2. Geneva, World Health Organisation, 2014.

38 Office of Disease Prevention and Health Promotion: Nutrient Assessment for DRI Review. 2016. http://health.gov/dietaryguidelines/dri/nutrient-assessment.asp (accessed April 22, 2016).

39 Willet W: Nutritional Epidemiology. New York, Oxford University Press, 1990.

40 Lauritzen L, Halkjaer LB, Mikkelsen TB, Olsen SF, Michaelsen KF, Loland L, Bisgaard H: Fatty acid composition of human milk in atopic Danish mothers. Am J Clin Nutr 2006; 84:190-196.

41 Mikkelsen TB, Osler M, Olsen SF: Validity of protein, retinol, folic acid and n-3 fatty acid intakes estimated from the food-frequency questionnaire used in the Danish National Birth Cohort. Public Health Nutr 2006;9:771778.

42 Rodriguez-Bernal CL, Ramon R, Quiles J, Murcia M, Navarrete-Muñoz EM, Vioque J, Ballester F, Rebagliato M: Dietary intake in pregnant women in a Spanish Mediterranean area: as good as it is supposed to be? Public Health Nutr 2013;16:1379-1389.

43 Bemrah N, Sirot V, Leblanc JC, Volatier JL: Fish and seafood consumption and omega 3 intake in French coastal populations: CALIPSO survey. Public Health Nutr 2009; 12:599-608. 
-44 Franke C, Verwied-Jorky S, Campoy C, TrakFellermeier M, Decsi T, Dolz V, Koletzko B: Dietary intake of natural sources of docosahexaenoic acid and folate in pregnant women of three European cohorts. Ann Nutr Metab 2008;53:167-174.

-45 Féart C, Alles B, Merle B, Samieri C, Barberger-Gateau P: Adherence to a Mediterranean diet and energy, macro-, and micronutrient intakes in older persons. J Physiol Biochem 2012;68:691-700.

-46 González S, Huerta JM, Fernández S, Patterson AM, Lasheras C: The relationship between dietary lipids and cognitive performance in an elderly population. Int J Food Sci Nutr 2010;61:217-225.

47 Koletzko B, Braun M: Arachidonic acid and early human growth: is there a relation? Ann Nutr Metab 1991;35:128-131.

-48 Carlson SE, Werkman SH, Peeples JM, Cooke RJ, Tolley EA: Arachidonic acid status correlates with first year growth in preterm infants. Proc Natl Acad Sci U S A 1993;90: 1073-1077.

49 Brenna JT: Arachidonic acid needed in infant formula when docosahexaenoic acid is present. Nutr Rev 2016;74:329-336.

50 Hadley KB, Ryan AS, Forsyth S, Gautier S, Salem N Jr: The essentiality of arachidonic acid in infant development. Nutrients 2016;8:216.
1 Yazdi PG: A review of the biologic and pharmacologic role of docosapentaenoic acid n-3. Version 2. F1000Res 2013;2:256

52 EFSA Panel on Dietetic Products, Nutrition and Allergies: Scientific opinion on nutrient requirements and dietary intakes of infants and young children in the European union. EFSA J 2013;11:3408.

53 Belgium Superior Health Council: Advies 9285 - Voedingsaanbevelingen Voor België 2016|FOD Volksgezondheid. 2016. http:// www.health.belgium.be/nl/advies-9285voedingsaanbevelingen-voor-belgie-2016.

54 D-A-CH: Referenzwerte fur die Nahrstoffzufuhr. Bern, Umschau, 2013.

55 Bundesamt für Gesundheit: Fette in der Ernährung-Aktualisierte Empfehlungen der Eidgenössischen Ernährungskommission. Suppl. zum Expert. Fette der Ernährung mit den Aktual. Empfehlungen. Zürich, Eidgenössische Ernährungskommission, 2012.

56 Health Council of the Netherlands: Dietary Reference Intakes: Energy, Proteins, Fats and Digestible Carbohydrates. Hague, Health Council of the Netherlands, 2001.
57 Ministers NC: Nordic Nutrition Recommendations 2012. Part 1: Summary, Principles and Use. Copenhagen, Nordic Council of Ministers, 2014.

58 Dobrzanska A, Charzewska J, Weker H, Socha P, Mojska H, Książyk J, Gajewska D, Szajewska H, Stolarczyk A, Marć M, Czerwionka- Szaflarska, Ryżko J, WąsowskaKrólikowska K, Chwojnowska Z, Chybicka A, Horvath A, Socha J: Normy żywienia zdrowych dzieci w 13 . Roku życia stanowisko polskiej grupy ekspertów.część i zapotrzebowanie na energię i składniki odżywcze. Pediatr Pol 2013;88:97-102.

59 Baviera JMB, Ferrús Pérez MA, Font Pérez G, Hardisson de la Torre A, Herrera Marteache A, Lorente Toledano F, Sánchez AM, Marti del Moral A, de Santos MRM, Martínez Larrañaga MR, Martínez López A, Martínez de Victoria Muñoz E, Nerín de la Puerta C, Pérez Martínez G, Picó Segura C, Pintó Solé MR, Pla Martínez A, Luis J, Cañavate R, Salas Salvadó J, Simal Gándara J: Informe del Comité Científico de la Agencia Española de Consumo, Seguridad Alimentaria y Nutrición (AECOSAN) Sobre Objetivos y Recomendaciones Nutricionales y de Actividad Física Frente a la Obesidad en el Marco de la Estrategia NAOS. Madrid, AECOSAN, 2014. 